\title{
Heterogeneity in relation to electrical and mineralogical properties of hematitic sandstone samples
}

\author{
Mohamed Mahmoud Gomaa ${ }^{1}$
}

Received: 10 March 2019 / Accepted: 30 March 2020 / Published online: 13 April 2020

(c) The Author(s) 2020

\begin{abstract}
Electrical properties of mixtures of composite materials are sensitive to texture between grains. Electrical measurements of hematite and sandstone composite mixture were performed in the frequency range $\left(5 \times 10^{-4} \mathrm{~Hz}-10^{5} \mathrm{~Hz}\right)$. This study is a trial to give more detailed information upon the effect of electrical properties and their relation to the ore composite mixture, its geochemical and spectrographic analyses. The composite mixture of the samples displays some similarity in the frequencydependent response of the electrical properties that follow Jonscher's universal law. The frequency dependence of electrical conductivity indicates that the sample behaves as a semiconductor material at relatively high frequencies. The spectra of the measured electrical properties vary strongly with the change of the concentration of the conductive elements and the texture of the specimens. The main change of the electrical properties is related to the conductor (saturation) concentration. This change does not increase monotonically with the increase in the conductor (saturation) concentration which may be attributed to the degree of heterogeneity between the grains (and texture). The interface between the grains controls the relatively low frequencies, whereas the bulk grain dominates the relatively high frequencies. The heterogeneity of the samples is an effective component in controlling the electrical properties of the composite mixtures.
\end{abstract}

Keywords Composite $\cdot$ Electric $\cdot$ Dielectric constant $\cdot$ Mixture $\cdot$ Hematitic sandstone

\section{Introduction}

Subsoil studies using noninvasive techniques are of great importance for many scientific branches (hydrogeology, waste observation and hydrocarbon research). It is a complex and difficult problem to interpret the complex electrical properties of heterogeneous mixtures. Electrical properties at dry condition of composite mixture of hematite sandstone indicate that interface between grains greatly affects the electrical properties of rocks. Hematite is one of the most important rocks (economically) that has high interface between grains and accordingly high electrical properties and has not been studied in detail. Increasing the content of alkali ions in the rock increases the electrical conductivity. Extensive studies were done on DC electrical properties of many materials, but relatively little works have been done on the AC electrical behavior (Gomaa 1996; Gomaa 2004a,

Mohamed Mahmoud Gomaa

mmmsgomaa@yahoo.com

1 Geophysical Sciences Department, National Research Centre, El-Tahrir St., Dokki 12311, Egypt b). DC measurements of current provide information on the conduction links present in samples. AC electrical properties give information about the conduction and insulation process in the samples (Dias 1972; Gomaa et al. 1999a, b, c). AC electrical response of any multicomponent mixture depends basically upon the volume fraction of conductor and insulator constituents of each individual component. De Lima and Sharma $(1991,1992)$ show that the effective electrical properties of shaly sands depend basically on the particle size, particle shape (Sen 1984), the effective conductivity and dielectric constant of the interstitial constituents (Sen 1989), and heterogeneity and randomness of the mixture and the frequency of the applied field (De Lima 1995).

The electrical properties of the iron ores samples (hematitic sandstone) were measured for samples occurring at East Aswan, in the Eastern Desert, and Bahariya Oasis, in the Western Desert. The electrical measurements have been made (dry) in the frequency range of $10 \mathrm{~Hz}$ up to $100 \mathrm{kHz}$ at room temperature $\left(\sim 20^{\circ} \mathrm{C}\right)$. The electrical response of hematitic sandstone samples was measured at different hematitic sandstone concentrations. The heterogeneity and randomness are a very big problem that control (the dominant) 
the electrical properties of the samples. We try to eliminate the effect of heterogeneity and randomness of the mixture by grinding the samples. The samples were ground and overturned in another instrument, $300 \mathrm{round} / \mathrm{m}$, for $3 \mathrm{~min}$ and finally squeezed under pressure $(140 \mathrm{kN})$. These samples (mixture) are supposed to be multicomponent system of sand/hematite/air, with an electrical response dependent upon the nature of the individual constituents (Knight and Nur 1987; Knight 1983). The mixture components of multicomponent system will be affected with the frequency and additions of conductor (hematite), leading to the transformation of the system, at a certain conductor concentration, from insulator to semiconductor (with distinct electrical and physical properties). Also, we will try to discuss the physical models and mechanisms of conduction and polarizations that are arise under different constituent concentrations.

The properties of the rock composite vary considerably with frequency (Olhoeft 1985). At low frequencies, effective conductivity is increasing with the increase in frequency and the effective permittivity is decreasing with the increase in frequency (Sen 1981; Vinegar and Waxman 1984). The typical response at low frequencies shows that the bulk AC conductivity is frequency independent, but at high frequency the conductivity increases with a behavior called universal power law (Jonscher 1999). Electrical characteristics may be due to geometric constituents or due to heterogeneities of the samples (Sen 1981; Knight and Endres 1990). Also, it may be connected to electrochemical procedures that arise at grain interfaces (Marshall and Madden 1959; Dias 1972). The electrochemical processes between charged grains lead to the presence of double layer around these particles. The polarization of that double layer under the effect of applying an electric field leads to the anomalous behavior of samples (Dukhin and Shilov 1974; Chew and Sen 1982). This is called the Maxwell-Wagner relaxation mechanism or the interface effect. This effect is responsible for many dispersive behaviors on grain surfaces or at the contact of any two materials.

Knight and Abad (1995) related the power law behavior to the sample texture. The random nature of the constituents within the samples is the main factor of the power law (Jonscher 1999; Gomaa e al. 2000, 2001). The conductivity of dry sandstone at room temperatures is $\sim 10^{-10} \mathrm{~S} / \mathrm{m}$, and its relative permittivity is $\sim 3-5$. The conductivity of dry hematite at room temperatures is $\sim 10^{-2}-10^{-3} \mathrm{~S} / \mathrm{m}$, and its relative permittivity is $\sim 25$. For a mixture of hematitic sandstone (hematite and sand), the interface between these two components gives high-permittivity values that are strongly frequency dependent (Chelidze and Gueguen 1999; Chelidze et al. 1999), which was argued to the polarization effects and surface conductivity. Without applying an oscillating electric field, ions are not under control to move. With applying that electric field, the charges are polarized leading to large dipoles and to giant apparent permittivity (Garrouch and Sharma 1994; Garrouch 2001). With increasing frequency, the charges do not have much time for polarization process and their values will be added to the conductivity because they will be in phase with the applied field.

Adding a small amount of conductor to the specimen constituents may lead to increase the conductance and may reduce the dielectric constant. All of these factors are resulted from physical processes at the interface of the grains. These reactions may be considered as surface contributions to the complex electrical conductivity of samples (Chelidze and Gueguen 1999; Chelidze et al. 1999). Orientation polarization or hopping of ions along the surface is the most probable polarization mechanism of charges (Chelidze and Gueguen 1999; Chelidze et al. 1999; Glover et al. 1994).

Polarization of non-conducting grains, coated with a conducting one, may lead to high dielectric values at low frequencies (Chelidze et al. 1999). This is an explanation that the addition of a small conductor quantity to a sample may result to a high-permittivity value at relatively lower frequencies. Also, the insulating layers that cover the conducting particles may result to a small increase in conductivity accompanied with a violent decrease in dielectric constant to relatively low values at high frequencies.

Hematite as a sedimentary rock deposit is thought to have precipitated by organic and/or chemical processes. The hematite is often found mixed together with other layers of quartz or chert. The chemical formula of hematite is $\mathrm{Fe}_{2} \mathrm{O}_{3}$, its empirical formula is $\mathrm{Fe}_{2}{ }^{3+} \mathrm{O}_{3}$, and its composition is nearly iron $70 \%$ from $100 \% \mathrm{Fe}_{2} \mathrm{O}_{3}$ and oxygen $30 \%$, its molecular weight $=159.69 \mathrm{gm}$.

\section{Aswan iron ore deposits}

Nubian sandstone (Cretaceous age) is overlained by fossiliferous calcareous sediments of Upper Cretaceous age. Its heavy minerals are mainly iron ores, zircon, tourmaline and futile (Shukri and Ayouty 1959). Lower horizons may be derived from local underlying basement rocks. Upper horizons are derived from the south. Nubian sandstone is found to be of marine origin (Attia 1955). It is (lithologically) composed of conglomerates, sandstones, sandy shales, clays, quartz bands in addition to some ferruginous sandstone.

Microscopically, the Nubian Sandstone Formation is composed of ferruginous sandstones in addition to some clay minerals that may contain some iron-bearing oolites (Nakhla and Shehata 1967). Sometimes, remnants of oolites may be found in a bulk of quartz grains that may be cemented with some crystalline hematite. Sandstones are partial recrystallized, and its grain sizes are smaller in samples of rich iron oxides. Some parts of the quartz grains may contain extremely small amounts of disseminated hematite. 
Ferruginous sandstones and clays, also, may contain grains of hematite-quartz or hematite-goethite-quartz (goethite replacing hematite partially).

Aswan iron ores are composed of (1) cryptocrystalline hydrated hematite $\left(\mathrm{Fe}_{2} \mathrm{O}_{3}-\mathrm{nH}_{2} \mathrm{O}\right)$, (2) microcrystalline hematite, (3) clay minerals, (4) quartz with subangular to subrounded form, (5) goethite and hydrogoethite (Nakhla and Shehata 1967). Due to relatively easier passing of the solutions through the matrix than through the oolites, then the matrix is more recrystallized than the oolites (Nakhla and Shehata 1967). Solutions in the samples show that they were formed from the partial or complete deposition of hematite or hydrated iron oxides in fissures or cracks after leaching them from oolites. Also, the chemical process of chemical solutions may lead to destroy the original structure of the oolites and the result of this process is a complete mixing of the mineral constituents (oolites and matrix). Sometimes, some anhedral detrital quartz grains may be found disseminated in the hematitic matrix.

The oolites have a wide range of variation in diameter ( 0.65 to $0.75 \mathrm{~mm})$. Also, two or more oolites may be found cemented together. Oolites may be found to be cemented of the core (iron-bearing component) and the shell (quartz, colloidal silica, ferruginous clay or a reworked oolite) (Gason et al. 1999). The shell is usually composed of turgite and hydrated silica (or clay) with zonal structure. The removal of iron from oolites forms grayish white oolites which are coated with calcite.

There is a wide range of chemical analysis and composition variation (Table 1, Nakhla and Shehata 1967). Semiquantitative spectrographic analyses of some sediments and iron ore samples are present in Table 2. Geochemical analyses of some important elements will be presented as follows (Goldschmidt 1954; Mason 1958; Taylor and Ahrens 1960; Ljunggren 1953, 1955a, b):

1. Iron presented as hydrated ferric oxides (turgite). The ferrous iron may be formed from partial reduction in ferric oxides by organic matter.

2. Silica may be present as free crystalline and/or cryptocrystalline and/or amorphous states, or it may be present as silicates (clay minerals).
Table 2 Semiquantitative spectrographic analysis (after Nakhla and Shehata 1967)

\begin{tabular}{lclll}
\hline Elements & $\begin{array}{l}\text { Detection } \\
\text { limit in ppm }\end{array}$ & Iron ore & $\begin{array}{l}\text { Ferruginous } \\
\text { sandstone }\end{array}$ & Ferruginous clay \\
\hline $\mathrm{Cu}$ & 1 & $30-200$ & $10-300$ & 10 \\
$\mathrm{Ni}$ & 1 & $8-30$ & $8-30$ & 10 \\
$\mathrm{Co}$ & 1 & $10-30$ & 10 & 10 \\
$\mathrm{Ti}$ & 1 & $80-100$ & 100 & 100 \\
$\mathrm{Cr}$ & 10 & $0-10$ & $0-10$ & $0-10$ \\
$\mathrm{~V}$ & 10 & 100 & $10-100$ & $10-100$ \\
$\mathrm{Zr}$ & 10 & $8-20$ & $10-100$ & 10 \\
$\mathrm{~Pb}$ & 100 & $0-100$ & $0-100$ & \\
\hline
\end{tabular}

Elements not detected at a concentration limit of $100 \mathrm{ppm}$ include $\mathrm{Cd}, \mathrm{Ga}, \mathrm{Ge}, \mathrm{Sn}, \mathrm{Nb}, \mathrm{Ta}, \mathrm{Sb}$ and $\mathrm{T}$

3. Calcium and gypsum may be connected with ferruginous sediments and may be occurred as carbonate or sulphate.

4. Magnesium may occur as magnesium silicates or magnesium carbonate associated with calcium carbonate.

5. There are some other minerals that may occur with inconsiderable amounts: manganese $(\sim 0.009 \mathrm{ppm})$, phosphorus adsorbed to the hydrated iron, sulfur as calcium sulfate, copper (10 to $100 \mathrm{ppm}$ ) associated with hydrated iron oxides and silica, titanium ( $100 \mathrm{ppm})$, nickel (8 to $30 \mathrm{ppm}$ ) (hydrated nickel silicates), chromium ( $10 \mathrm{ppm})$, zirconium ( 8 to $100 \mathrm{ppm})$.

\section{Experimental electrical procedures}

Ten hematitic sandstone samples were measured electrically. Samples are composed mainly of iron deposits from East Aswan, Eastern Desert, Cairo, Egypt. The measurements were done at dry atmosphere with a temperature of $\sim 20^{\circ} \mathrm{C}$. The electrical measurements were conducted in the frequency range $\left(5 \times 10^{-4} \mathrm{~Hz}\right.$ from $\left.10^{5} \mathrm{~Hz}\right)$ with Hioki 3522-50 LCR Hitester Impedance Analyzer. The detailed description, of the electrical cell used in the measurement, is described in Fig. 1. Geological samples are
Table 1 Chemical analyses of east Aswan iron ore deposits (after Nakhla and Shehata 1967)

\begin{tabular}{|c|c|c|c|c|c|c|}
\hline \multirow[t]{2}{*}{ Type } & \multicolumn{6}{|c|}{ Percentage of total } \\
\hline & & Iron $\%$ & $\mathrm{Fe}_{2} \mathrm{O}_{3} \%$ & $\mathrm{FeO} \%$ & $\mathrm{CaO} \%$ & $\mathrm{SiO}_{2} \%$ \\
\hline \multirow[t]{2}{*}{ Iron ore } & Range & $39.45-61.04$ & $56.41-87.01$ & $0.00-0.25$ & $0.04-7.95$ & $4.07-28.62$ \\
\hline & Average & 49.12 & 60.13 & 0.10 & 2.61 & 9.21 \\
\hline \multirow[t]{2}{*}{ Ferruginous sandstone } & Range & $0.74-37.29$ & $1.06-53.01$ & $0.00-0.28$ & $0.00-12.87$ & $18.55-91.84$ \\
\hline & Average & 30.12 & 43.01 & 0.09 & 2.41 & 51.87 \\
\hline \multirow[t]{2}{*}{ Ferruginous clay } & Range & $4.09-37.59$ & $5.84-51.48$ & $0.01-2.00$ & $0.24-4.49$ & $11.91-70.57$ \\
\hline & Average & 30.90 & 44.04 & 0.12 & 2.45 & 40.27 \\
\hline
\end{tabular}




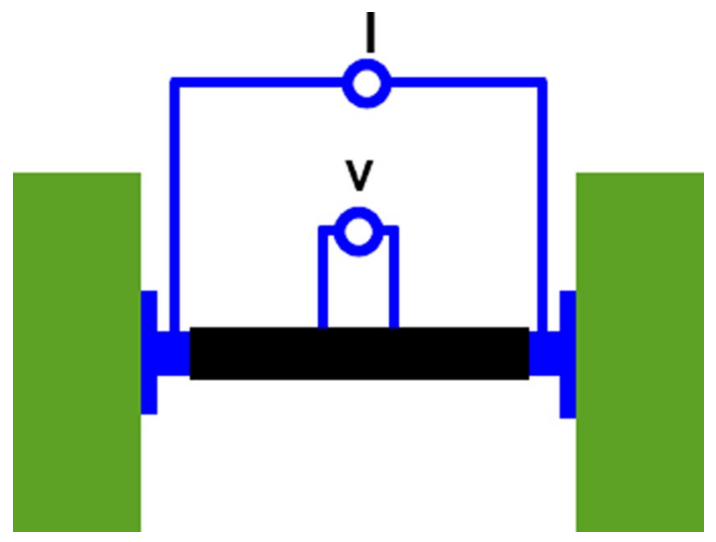

Fig. 1 A schematic representation of the sample holder used for the measurements

heterogeneous, so the samples were gathered from different locations at Aswan area. To be sure that the samples are representative for the chosen area, it was crashed in a crashing machine until it was totally homogeneous. The particle size was nearly in the order of $\sim 1 \mu \mathrm{m}$. Samples were flipped for more than $5 \mathrm{~min}$ in another instrument with nearly $300 \mathrm{Round} / \mathrm{m}$. The final mixture was compressed under pressure of nearly $140 \mathrm{KN}$ in the form of small tablets. The samples dimensions were removed from the electrical calculations, and the diameter was chosen to be much bigger than their thickness.

The complex impedance $Z$ is as follows

$Z=R_{\mathrm{s}}-i X_{\mathrm{s}}$

$R_{\mathrm{s}}$ is the real impedance of the sample, $X_{\mathrm{s}}=1 / w C_{\mathrm{s}}$ is the sample reactance and $C_{\mathrm{s}}$ is the series capacitance.

The complex resistivity is as follows

$\rho^{*}=Z \times(A / d)$

$A$ is the area cross section and $d$ is the sample thickness.

The real impedance is calculated as follows

$\operatorname{Re} Z=R_{\mathrm{s}}$

The imaginary impedance is calculated as follows

$\operatorname{Im} Z=1 / w C_{\mathrm{s}}$

The resistance is calculated as follows

$\rho=R_{\mathrm{p}} \times(A / d)$

The permittivity is calculated as follows

$\varepsilon^{\prime}=C_{\mathrm{p}} / C_{0}$

and

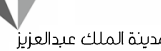

KACT العزيز
$C_{\mathrm{o}}=(A / d) \varepsilon_{0}$

$w$ is the angular frequency, $R_{\mathrm{p}}$ is the parallel resistance, $C_{\mathrm{p}}$ is the parallel capacitance, $\varepsilon_{0}$ is the permittivity of free space $\left(8.85 \times 10^{-12} \mathrm{~F} / \mathrm{m}\right), G_{\mathrm{p}}$ is the parallel conductance, and $C_{\mathrm{p}}$ is the parallel capacitance.

\section{Interpretation and discussion of results}

The general behavior of the electrical conduction in the rock samples may be common for all rock mixture material. Increase in conductor is in high relation to the increase in the conductivity and the dielectric constant and other general electrical measured parameters. The conductivity increases because the electrical current is transported by the ions in conductor elements or grains in the sample. The dissolved ions and oxides in the samples are the main responsible factor for the conduction currents. The increase in air gaps between grains due to the presence of conductor decreases the permittivity. Also, there are many factors that may influence the electrical properties, e. g., chemical reaction, frequency, pressure, conduction elements and many other factors. All these factors are directly or indirectly change the results of the electrical properties of the samples (Gomaa 2004a, b).

The specimens are composed of iron ore (mainly hematite), ferruginous sandstone and ferruginous clay. The iron ore (hematite) and the ferruginous clay are supposed to be semiconductors, while the ferruginous sandstone is supposed to be an insulator. According to the measured electrical properties of the samples, the conductivity of these samples ranges in values from insulator to semiconductor materials.

The effective electrical properties (electrical conductivity and permittivity) of some shaly sands show a high dependence on the conductor volume content and on the frequency of the applied electric field (De Lima and Sharma 1991, 1992, 1995).

Figure 2 shows the variation of the conductivity as a function of frequency for Aswan iron ore deposits with different concentrations of samples. When the sample is dry, it is supposed that the pores are completely filled with air. Additions of conduction paths in the sample are a consequence of the increase in the conductor concentration in the sample that leads to the increase in the conductivity at a certain frequency (Fig. 2). The effect of the frequency on conductivity is clear to increase the conductivity until it reaches the value of the highest conductor component in the sample. At that value, the conductivity value begins to saturate at a certain value $\sim 10 \mathrm{MHz}$ (Fig. 2, beyond our measurements) (Knight and Nur 1987; Knight and Endres 1990). 
Fig. 2 âVariation of the conductivity with frequency for Aswan iron ore deposits, for samples

$1(\boldsymbol{\Delta}), 2(\bullet), 3(*), 4(\bullet)$ and 5 (荞, respectively

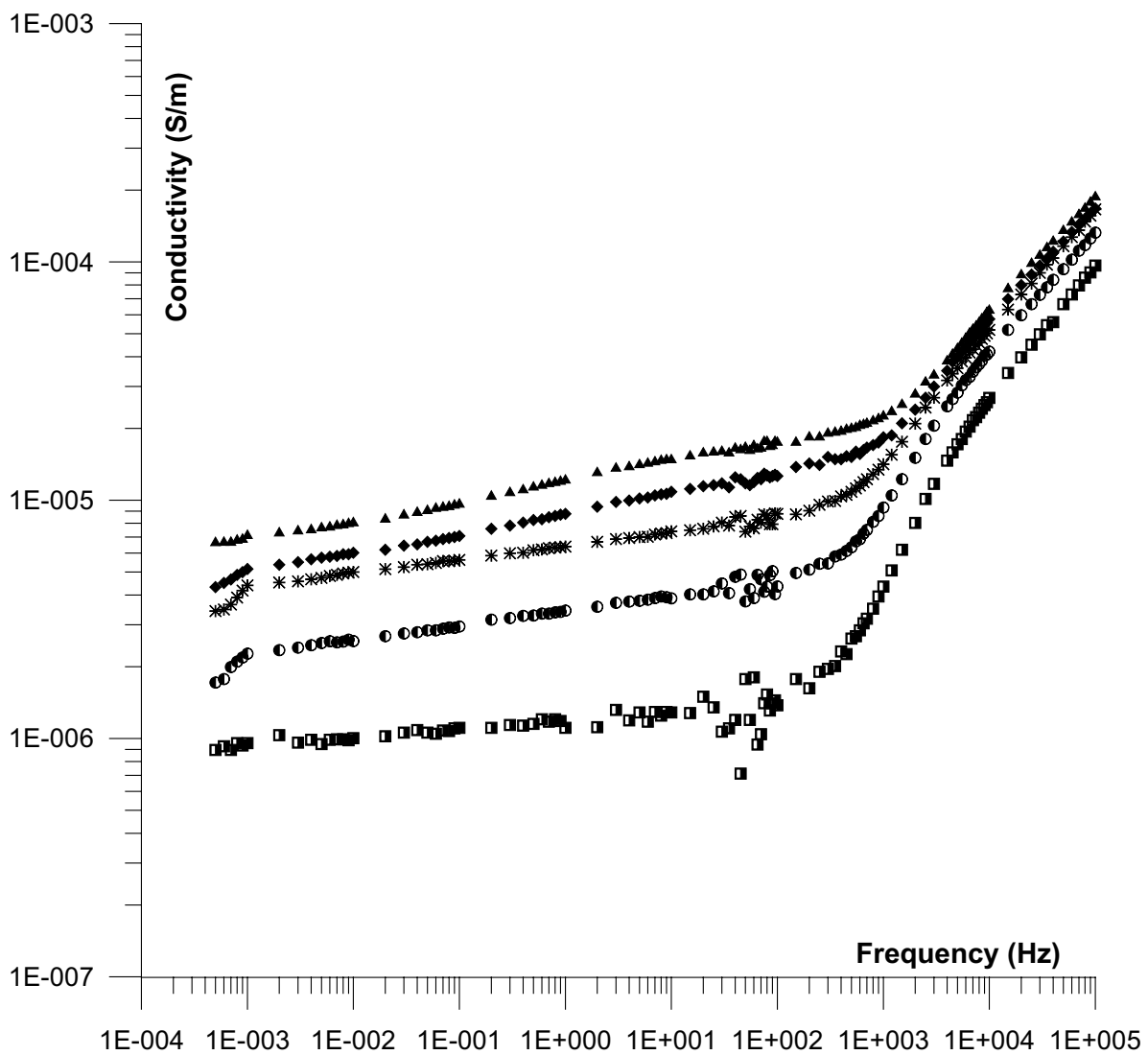

The definition of the critical concentration (percolation threshold) is the concentration above which the semiconductor grains start to make the first unbroken track between the two electrodes. At this group of measurements, the critical concentration could not be defined exactly. This may be due to the fact that the samples were above that critical concentration before the addition of water. With the increase in semiconductor (water) concentration, more unbroken tracks will be formed, and accordingly, more conductivity values will be added to the original value of the conductivity, due to the increase in conduction current.

Conductivity dispersion phenomenon was first discussed and interpreted by using Jonscher's law (Jonscher 1999). The interaction between all pairs of dipoles (polarization process) is distinguished by $n$ parameter. If $n$ equals 1 (unity), then the case will be called Debye case. At this case, there is no interaction (negligible) between the adjoining dipoles. If the value of $n$ changes, to be less than unity, due to the increase in interaction, then the case may be changed to be Cole-Cole case or Cole-Davidson case, etc.

Figures 2, 3 and 4 show the conductivity dispersion for all the samples in detail. It is obvious that there is a frequency-dependent behavior of conductivity on frequency for all the samples. At relatively low frequencies (nearly below $100 \mathrm{~Hz}$, for relatively low saturations), the conductivity curves show nearly no dispersion and relatively constant slope that is parallel to the $X$-axis. The independent behavior of conductivity may be attributed to the direct current from the semiconductor grains (DC conduction).

As a general rule, the conductivity has a characteristic $w^{n}$ dependence, with $n \sim 0.9$, and $w$ is the angular frequency, with the increase in frequency where $n$ is the power law exponent. The value of $n$ generally varies between 0 and 1 according to many different parameters (general texture of sample). The influence of interaction between the grains and movable charges within the samples is represented by that exponent $n$. At relatively higher conductor saturations, the flat dispersion (no dispersion) of conductivity extends to higher frequencies. The crossover frequency changed from one saturation to another. The crossover frequency is the frequency above which the slope of the conductivity or dielectric constant is changed. The crossover frequency is a declaration of the increase in the unbroken links between the electrodes.

Figure 3 shows the change of the dielectric constant as a function of frequency for Aswan iron ore samples. In the dry state of the samples, the pores are assumed to be fully filled with air voids while, when the samples are not dry, it is assumed that there is a small portion of that cover the surface of the grains, and consequently, the volume of air unfilled space or interval in the sample decreases. As a consequence of that, generally, the dielectric constant increases many

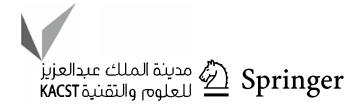


Fig. 3 Variation of the real part of the dielectric constant with frequency for Aswan iron ore deposits, for samples $1(\mathbf{A})$ , 2 (•), 3 (*), 4 (\) and 5 (ロ), respectively

Fig. 4 Variation of the dielectric loss with frequency for Aswan iron ore deposits, for samples $1(\mathbf{\Delta}), 2(\bullet), 3(*), 4(\mathbf{\bullet})$ and 5 (Б), respectively
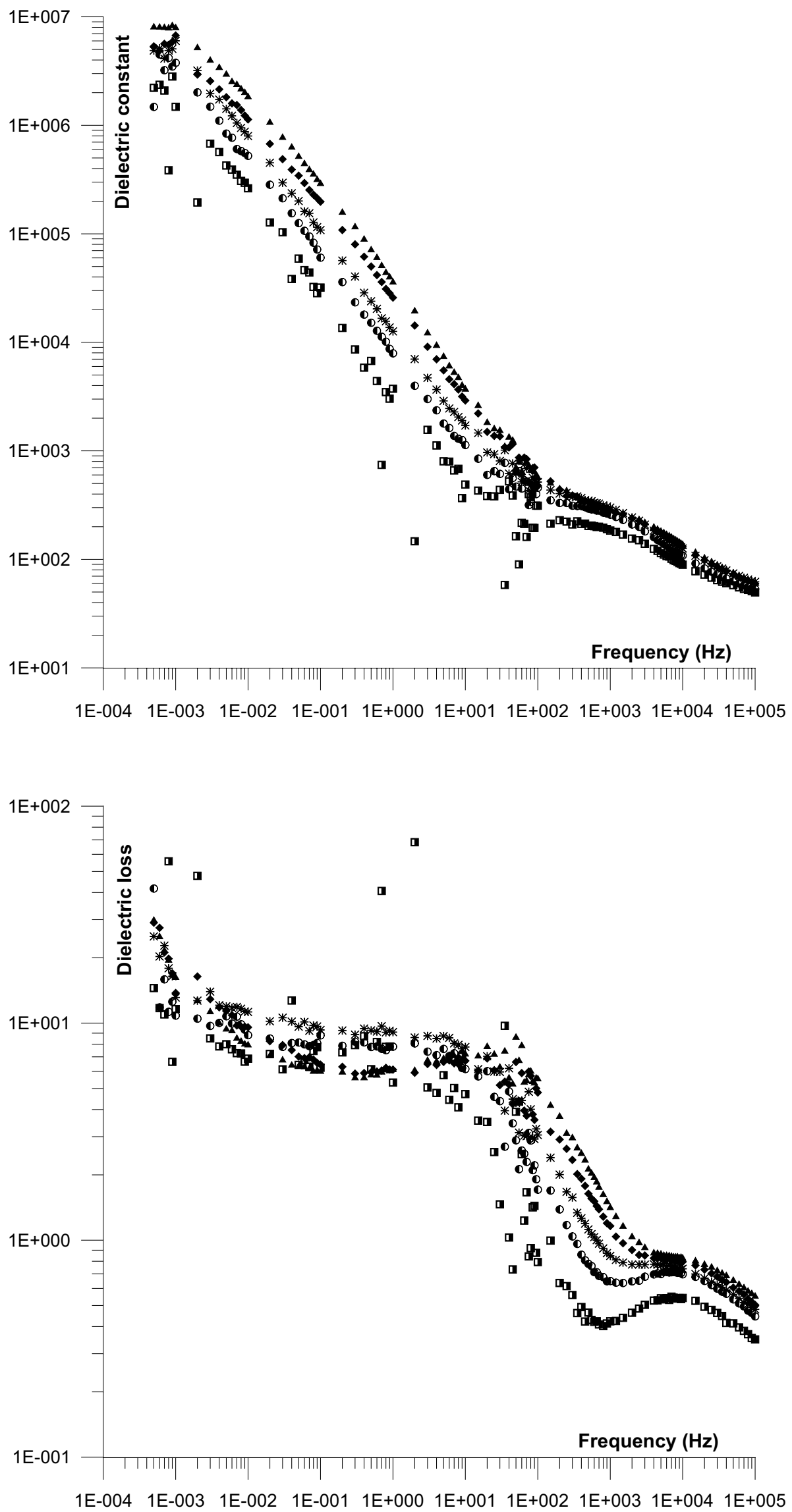
times above the usual values. There will be more increase in dielectric constant with the mutual increase in the saturation concentration up to a certain level. That certain level is assumed to be when a real link is established between the grains. Due to that phenomenon, the samples of the higher saturations have the highest dielectric constant (before the critical concentration) and the other samples of the highest saturations have the lowest dielectric constant (after the critical concentration). When the grains are in contact with each other, the air gaps between them are not present and the dielectric constant returns to its normal value (Fig. 3, Gomaa 2020). From the curves, it can be noticed that there is a dielectric constant $\left(\varepsilon^{\prime}\right)$ which has a frequency dependence $\left(\varepsilon^{\prime} \propto w^{n-1}\right)$, that is, a general trend for, nearly, all the samples, with $n \sim 0.8$. As it can be compared with Figs. 2, 3 generally has, also, with the variation of frequency, two regions with different slopes. The low-frequency slope (less than $100 \mathrm{~Hz})$ has a general steep trend $(\approx-0.8)$ and the steep trend decreases until slightly until it reaches a slope of $\approx-0.1$ for high frequencies $(1 \mathrm{kHz})$. There is a broad distribution of relaxation times at low frequencies. This is clear from the high dispersion of the dielectric constant. This broad distribution may be attributed to the different and wide variable distances between grains (Jonscher 1999).

Figure 4 shows the change of dielectric loss with frequency for Aswan iron ore samples $\varepsilon^{\prime \prime}$. The dielectric loss is a different method of representation to interpret the conductivity $\sigma$ as $\sigma=w \varepsilon^{\prime \prime}$. The dielectric losses with frequency curves have nearly the same slope for all samples. At low frequency, there is no dispersion of the dielectric loss with frequency (up to $\sim 100 \mathrm{~Hz}$ ). After that flat response (at higher frequencies), there is a very high dispersion decrease in dielectric losses with frequency increase followed by a less dispersion response at higher frequencies.

All the curves are plotted in Fig. 5a. The other samples are plotted in Fig. 5b as a magnification for the overlap of the curves to notice the detailed differences between these curves with the increase in concentration. Figure 5a, b shows the complex impedance plane representation of the sample at different concentrations. As a general interpretation, the low saturation shows an arc represented at the impedance plane. When the saturation increases, this arc is expanded to higher values and to make a part of a depressed semicircle or to an arc of a depressed semicircle at higher saturations. The existence of different grain sizes in the samples leads to the initiation of many relaxation time constants in the complex impedance plane. Figure 5a shows the impedance plane (or Nyquist plot) for all the samples. Sample 5 (lower saturation) has the shape of an arc that has the highest imaginary impedance value compared to the other samples. The other samples are presented in Fig. 5b. With the increase in saturation, there is another semicircle that appears in addition to the first semicircle. The first semicircle impedance demonstrates the grain itself. The second semicircle impedance demonstrates the interface between the grains. The last sample (sample 1, Fig. 5b) shows two semicircles (for grain and interface) in addition to a small tail that may represent the DC conduction or the electrode effect of the sample. The increase in the slope of the arc and its movement towards a semicircle is an indicator of the increase in the unbroken links of the conducting medium (water).

\section{Conclusion}

Electrical properties of 5 hematitic sandstone samples from the East Aswan area, Eastern Desert, Egypt, have been established. Complex impedance measurements with the increase in saturation, at room temperature $\left(\sim 20^{\circ} \mathrm{C}\right)$, were accomplished in the frequency range from $5 \times 10^{-5}$ $\mathrm{Hz}$ up to $10^{5} \mathrm{~Hz}$. The heterogeneity of the samples is an effective component in controlling the electrical properties of the composite mixtures. The dielectric constant behavior was distinguished by two relaxation processes that are represented by the 'universal Jonscher's law.' The conductivity dependence on frequency showed a classical relaxation behavior that, also, follows the universal Jonscher's law. It has been observed that while the frequency being increases, the conductivity consequently increases. We try to establish the relation between the samples group of minerals and their connection with the electrical properties. The frequency dependence of electrical conductivity indicates that the sample behaves as a semiconductor material at relatively high frequencies. The spectra of the measured electrical properties vary strongly with the change of the concentration of the conductive elements and the texture of the specimens. The main change of the electrical properties is related to the conductor (saturation) concentration. The change may be attributed to the degree of heterogeneity between the grains (saturation and texture). The interface between the grains controls the relative low frequencies, whereas the bulk grain dominates the relatively high frequencies. The heterogeneity of the samples is an effective component in controlling the electrical properties of the composite mixtures. The difference in the electrical properties may be attributed to the degree of local heterogeneity in the sample. It can be found that the electrical conductivity values are strongly 
(a)

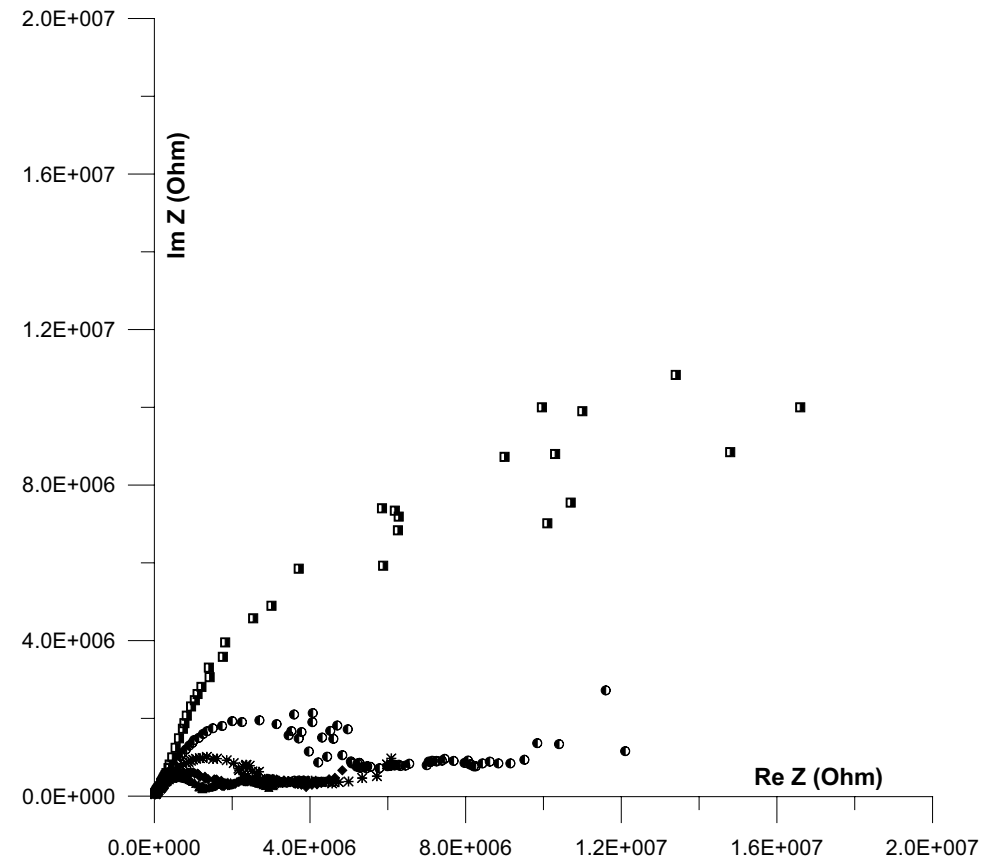

(b)
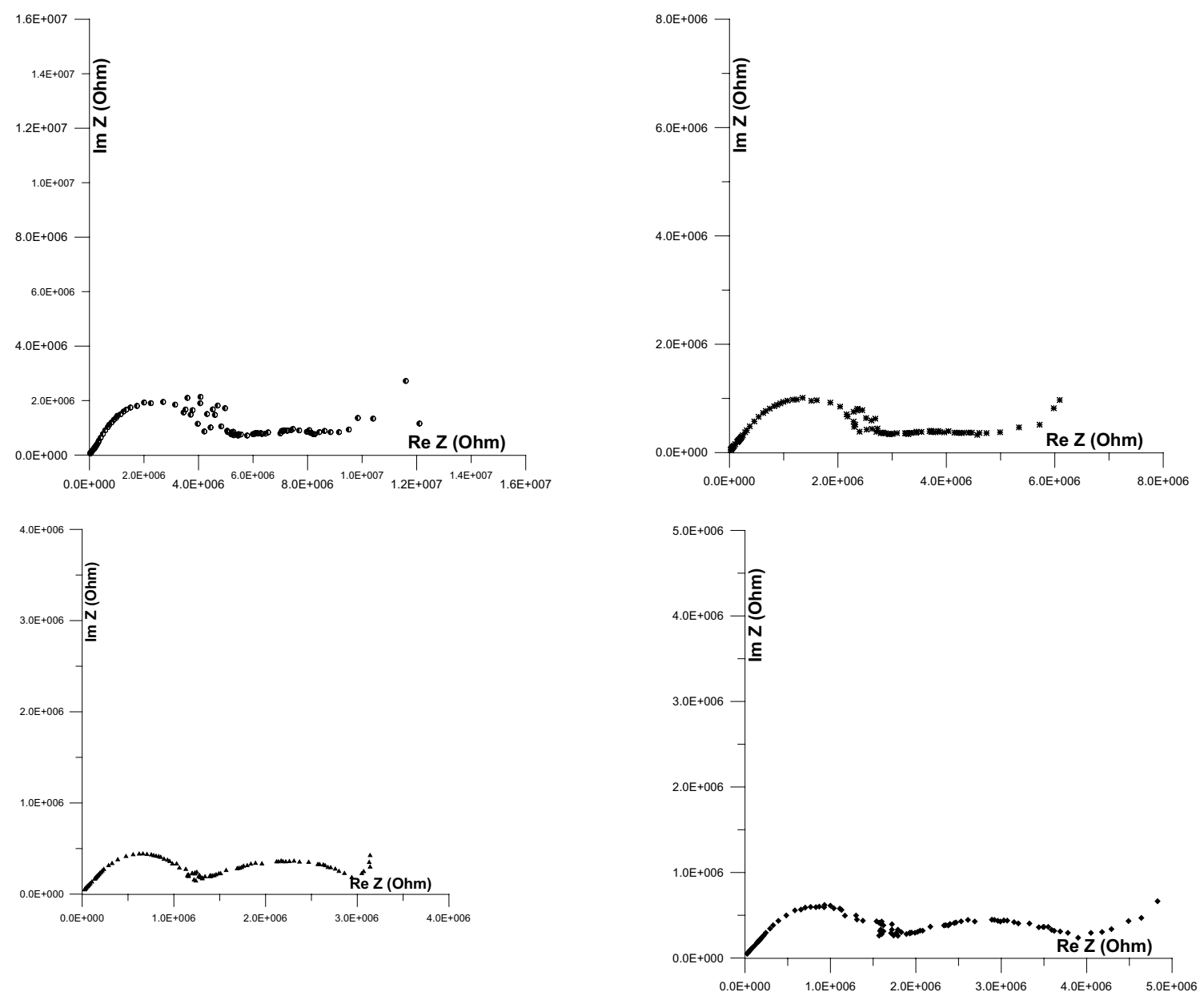
4 Fig. 5 a Variation of the complex impedance with frequency for Aswan iron ore deposits, for samples $1(\mathbf{\Delta}), 2(\bullet), 3(*), 4(\boldsymbol{O})$ and 5 (ם), respectively. b Variation of the complex impedance with frequency for Aswan iron ore deposits, for samples $2(\diamond), 3(*), 4(\mathbf{C})$

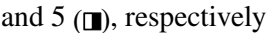

dependent on both the conductor (saturation) concentration and frequency.

Funding No funding.

\section{Compliance with ethical standards}

Conflict of interest The authors declare that they have no conflict of interest.

Open Access This article is licensed under a Creative Commons Attribution 4.0 International License, which permits use, sharing, adaptation, distribution and reproduction in any medium or format, as long as you give appropriate credit to the original author(s) and the source, provide a link to the Creative Commons licence, and indicate if changes were made. The images or other third party material in this article are included in the article's Creative Commons licence, unless indicated otherwise in a credit line to the material. If material is not included in the article's Creative Commons licence and your intended use is not permitted by statutory regulation or exceeds the permitted use, you will need to obtain permission directly from the copyright holder. To view a copy of this licence, visit http://creativecommons.org/licenses/by/4.0/.

\section{References}

Attia MI (1955) Topography, geology and iron-ore deposits of the district east of Aswan. Geological Survey, Cairo, Egypt, p 262

Chelidze T, Gueguen Y (1999) Electrical spectroscopy of porous rocks: a review-I. Theoretical models. Geophys J Int 137:1-15

Chelidze T, Gueguen Y, Ruffet C (1999) Electrical spectroscopy of porous rocks: a review-II. Experimental results and interpretation. Geophys J Int 137:16-34

Chew WC, Sen PN (1982) Dielectric enhancement due to electrochemical double layer: thin double layer approximation. J Chem Phys 77(9):4683-4693

De Lima OAL (1995) Water saturation and permeability from resistivity, dielectric, and porosity Logs. Geophysics 60(6):1751-1764

De Lima OAL, Sharma MM (1991) Water conductivity and saturation effects on the dielectric response of shaly sands. In: 32nd annual logging symposium on transactions of society of petrophysicists and well-log analysts, paper G

De Lima OAL, Sharma MM (1992) A generalized Maxwell-Wagner theory for membrane polarization in shaly sands. Geophysics 57:789-799

Dias CA (1972) Analytical model for a polarizable medium at radio and lower frequencies. J Geophys Res 77(25):9445-9456

Dukhin SS, Shilov VN (1974) Dielectric phenomena and the double layer in disperse systems and polyelectrolytes. Wiley, New York

Garrouch AA (2001) Effect of wettability and water saturation on the dielectric constant of hydrocarbons rocks. In: 41st annual logging symposium SPWLA, (2000) paper NN
Garrouch AA, Sharma MM (1994) The influence of clay content, salinity, stress and wettability on the dielectric properties of brine-saturated rocks: $10 \mathrm{~Hz}$ to $10 \mathrm{MHz}$. Geophysics 137:909-917

Gason SJ, Boger DV, Dunstan DE (1999) Rheo-optic Geological evidences on the paleogeography of the Nubian Sandstone. Langmuir 15:7446-7453

Glover PWJ, Meredith PG, Sammonds PR, Murrel SAF (1994) Ionic surface electrical conductivity in sandstone. J Geophys Res 99(B11):21635-21650

Goldschmidt VM (1954) Geochemistry. University Press, Oxford, p 730

Gomaa (1966) Frequency response study on iron ore bearing rock samples. M. Sc. Thesis, Cairo University, Egypt

Gomaa MM (2004a) Interpretation of AC electrical properties of humid sand and effect of water. In: 32 nd international geological congress IGC, 20-28 August, poster presentation in session "T25.04-rock physics versus lithology", Florence, Italy

Gomaa MM (2004b) Induced polarization study on iron ore bearing rock samples. Ph. D. Thesis, Cairo University, Egypt

Gomaa MM (2020) Kaolinite under pressure at audio frequency range and its electrical features. NRIAG J Astron Geophys 9(1):176-189

Gomaa MM, Hussain SA, El-Diwany EA (1999a) Electrical properties of heterogeneous systems (hematitic sandstone) and its interpretation. In: 2nd international conference on multivariate scattered data fitting, April 15-20, Puerto Vallarta, Jalisco, Mexico

Gomaa MM, Hussain SA, El-Diwany EA, Bayoumi AE, Ghobashy M (1999b) Pseudo-random network modelling of electrical properties of natural hematitic sandstone. In: 61st technical programme meeting: European Association of Geoscientists and Engineers (EAGE), Oral 2022, Session "Rock Physics II", 7-11 June, Helsinki Fair Centre, Finland

Gomaa MM, Hussain SA, El-Diwany EA, Bayoumi AE,., Ghobashy M (1999c) Renormalization group modeling of AC electrical properties of natural hematitic sandstone including texture effects. In: 69th annual international meeting: Society of Exploration Geophysics (SEG) and international exposition, session "Borehole/rock physics-characterization of rock and fluid properties", Oral PHRP7, Oct. 31-Nov. 5, Houston, Texas, pp 204-207

Gomaa MM, Hussain SA, El-Diwany EA, Bayoumi AE, Ghobashy M (2000) Modeling of AC electrical properties of humid sand and the effect of water content. In: 70th annual international meeting: Society of Exploration Geophysics (SEG) and international exposition, session "Rock properties/borehole: rock physics 1", Oral RPB6.7, Calgary, Alberta, Canada, 6-11 August, pp 1850-1853

Gomaa MM, Hussain SA, El-Diwany EA, Bayoumi AE, Ghobashy M (2001) AC electrical properties of kaolinite under pressure-pseudo random network modeling. In: 63rd technical programme meeting: European Association of Geoscience and Engineering (EAGE), Poster P054, session "Vertical electrical sounding and induced polarization and magneto-Telluric", 11-15 June, RAI, Amesterdam, The Netherlands

Jonscher AK (1999) Dielectric relaxation in solids. J Phys D Appl Phys 32:R57-R70

Knight R (1983) The use of complex plane plots in studying the electrical response of rocks. J Geomagn Geoelectr 137:767-776

Knight R, Abad A (1995) Rock/water interaction in dielectric properties: experiments with hydrophobic sandstones. Geophysics 60(2):431-436

Knight RJ, Endres AL (1990) A new concept in modeling the dielectric response of sandstones: defining a wetted rock and bulk water system. Geophysics 55:586-594

Knight RJ, Nur A (1987) The dielectric constant of sandstones, $50 \mathrm{kHz}$ to $4 \mathrm{MHz}$. Geophysics 52:644-654 
Ljunggren P (1953) Some data concerning the formation of manganiferous and ferriferous bog ores. Geol Foren Stockholm Forh 75:277-297

Ljunggren P (1955a) Differential thermal analysis and X-ray examination of Fe and Mn ores. Geol Foren Stockholm Forh 77:135-147

Ljunggren $\mathrm{P}$ (1955b) Geochemistry and radioactivity of some manganese and iron bog ores. Geol Foren Stockholm Forh 77:33-44

Marshall DJ, Madden TR (1959) Induced polarization, a study of its causes. Geophysics XXIV(4):790-816

Mason B (1958) Principles of geochemistry. Wiley, New York, p 310

Nakhla FM, Shehata MRN (1967) Contributions to the mineralogy and geochemistry of some iron-ore deposits in Egypt (UAR). Miner Depos 2:357-371

Olhoeft GR (1985) Low frequency electrical properties. Geophysics 137:2492-2503

Sen PN (1981) Dielectric anomaly in inhomogeneous materials with application to sedimentary rocks. Appl Phys Lett 39(8):667-668
Sen PN (1984) Grain shape effects on dielectric and electrical properties of rocks. Geophysics 49:586-587

Sen PN (1989) Unified models of conductivity and membrane potential of porous media. Phys Rev B 137:9508-9517

Shukri NM, Ayouty A (1959) The mineralogy of the Nubian Sandstone in Aswan. Bull Inst Desert Egypt 3(2):65-88

Taylor SR, Ahrens LH (1960) Spectrochemical analysis. In: Smales AA, Wager LR (eds) Methods in geochemistry. Interscience, New York, pp 81-110

Vinegar HJ, Waxman MH (1984) Induced polarization of Shaly sands. Geophysics 49:1267-1287

Publisher's Note Springer Nature remains neutral with regard to jurisdictional claims in published maps and institutional affiliations. 